\title{
Notes on types of some Acacia species (Fabaceae, Mimosoideae) at the National Herbarium of New South Wales (NSW)
}

\author{
P.G. Kodela
}

\begin{abstract}
Kodela, P.G. (National Herbarium of New South Wales, Royal Botanic Gardens, Mrs Macquaries Road, Sydney, N.S.W. 2000, Australia) 1998. Notes on types of some Acacia species (Fabaceae, Mimosoideae) at the National Herbarium of New South Wales (NSW). Telopea 7(4): 419-423. The typification of eight species of Acacia is discussed, and lectotypes are here selected for six of these species: Acacia adsurgens, A. ancistrocarpa, A. cambagei, A. caroleae, A. rhodoxylon and A. shirleyi. The previously designated neotype of $A$. cambagei is now unnecessary.
\end{abstract}

\section{Introduction}

While editing species treatments for the Flora of Australia it became apparent that the typification of a number of Acacia species required clarification. Lectotypes are selected here for several species to obviate further confusion and maintain the traditional and current usage of the names.

1. Acacia adsurgens Maiden \& Blakely, J. Roy. Soc. Western Australia 13: 28, pl. 20, figs 6-10 (1928)

T: 35 miles [56 km] NE of Camp 2, N.T., 7 June 1911, G.F. Hill 261 (in late flower); lecto (here chosen): NSW 359728; isolecto: MEL 2046228 n.v.; 40 miles [64 km] W of Camp 4, Lander Ck, N.T., 21 June 1911 [1914 on NSW \& MEL specimen labels, 1911 on an original label with a MEL specimen as well as being in the protologue confirms that 1911 was the collection year], G.F. Hill 360 (protologue: in late flower \& very early fruit); paralecto: K n.v., MEL (2 sheets) n.v., NSW 359729.

Lectotypification follows the earlier but unpublished selection by M.D. Tindale as deduced from her determinavit slips dated '21 Apr 1988' on the sheets at NSW. The above specimens were cited by Maiden and Blakely who would have seen the NSW sheets when preparing the protologue. The specimen with the better flowering material has been selected as the lectotype, i.e. NSW 359728. Original sketches and notes at NSW show that G.F. Hill 360 (probably NSW 359729) was used by the artist Miss E. King for figs 6 (branchlet with flowering spike) and probably 7 (attached phyllode base showing pulvinus and gland) in Plate 20, while G.F. Hill 261 (probably NSW 359728) was used for the ovary and flowers illustrated in figs 8-10. If NSW 359729 was the basis for fig. 6 , the spicate inflorescence has since been detached from the specimen and lost. Both NSW specimens have a pale blue 'National Herbarium of Victoria, Melbourne' label as well as a NSW label. At MEL one of the of sheets of Hill 360 (ex NSW), containing rather poor specimens, was seen by Maiden while the other material of Hill 360 and Hill 261 appears not to have been seen by the authors (J. Ross, pers. comm.). 
2. Acacia ancistrocarpa Maiden \& Blakely, J. Roy. Soc. Western Australia 13: 31, pl. 21, figs 1-6 (1928)

T: between Minderoo and Globe Hill, Ashburton R., W.A., 29 Sep 1905, A. Morrison; lecto (here chosen): NSW 371987; isolecto: E n.v., K n.v., PERTH n.v.; Barrow Creek, N.T., May 1922, S.A. White 81; paralecto: K n.v., MEL n.v., NSW 371986; Darwin to Pine Creek, N.T., Aug 1914, H.I. Jensen per C.E.F. Allen 209; paralecto: NSW 371985.

Of the above three collections cited by Maiden \& Blakely, the specimen NSW 371987 collected by Morrison has been selected as the lectotype, because: (i) it would have been seen by the authors; (ii) it fits the protologue description; (iii) it was illustrated by Margaret Flockton for Plate 21 (top half of branchlet with legumes and broader phyllode in fig. 1 and part of an open legume showing a seed in fig. 6); and (iv) the specific epiphet refers to the more or less hooked apex of the fruit which this specimen shows best. The specimen collected by White (NSW 371986) was also used to illustrate $A$. ancistrocarpa in Plate 21, i.e. the lower half of the branchlet with spikes and narrower phyllode (fig. 1) and figs 2-5.

3. Acacia cambagei R.T. Baker, Proc. Linn. Soc. New South Wales 25: 661, pl. 42 (1900, published 1901)

T: Bourke, [N.S.W.], May 1900, R.H. Cambage; lecto (here chosen): NSW 358545 (ex Cambage Herbarium, Sydney).

This sheet consists of two mounted branchlets with inflorescences and an attached packet of legumes. The legumes were contained in an envelope labelled 'Pera Bore, Bourke 12.01' (now in a plastic bag with original envelope), but are not part of the type material, since they appear to have been collected in December 1901 which is after the publication date of this species. However, the flowering specimens are believed to be type material that would have been seen by Baker because: (i) location details cited by Baker as 'Bourke, N.S.W., and northward to Queensland (R.H. Cambage)' imply that the type material was collected by R.H. Cambage near Bourke; (ii) the specimens collected in May 1900 pre-date the publication of Part IV of Vol. 25 of the Proceedings (i.e. May 20th 1901) in which A. cambagei was published; and (iii) although somewhat stylised, the line illustration of a flowering branchlet in Plate 42 drawn by Baker appears to have been based on part of the right-hand specimen of NSW 358545 (though possibly a reversed image to the mounted specimen). Other material would have been available for the description and illustration of the legume(s).

Because a type could not be located at one stage, L. Pedley, Taxon 33: 523 (1984), designated a neotype (viz. 10 miles [16.1 km] W of Bourke on Wanaaring Rd, May 1971, G.M. Cunningham 574 (NSW 265597)) in his proposal to conserve A. cambagei against $A$. georginae F.M. Bailey. See Pedley, loc. cit., for further discussion of Cambage's specimens and Baker's original description. The neotype is now superfluous with the finding of original type material (ICBN Art. 9: 13).

\section{Acacia caroleae Pedley, Austrobaileya 1: 132, fig. 9I (1978)}

Based on A. doratoxylon A. Cunn. var. angustifolia Maiden, J. E Proc. Roy. Soc. New South Wales 53: 217 (1920). T: Eidsvold, Qld, Nov 1918, T.L. Bancroft 32 (fruiting specimen); lecto (here chosen): NSW 417151; isolecto: BRI, K; Eidsvold, Qld, Bancroft 32; paralecto: ?K (Aug 1918) n.v., NSW 417155 (May 1917), NSW 417142 (Nov [?Aug] 1918), NSW 417148 (Aug [?Nov] 1918); Eidsvold, Qld, T.L. Bancroft s.n., Aug 1918; possible paralecto: BRI, NSW 417137 \& 417140.

Pedley cited the type of A. caroleae as 'Eidsvold, Aug 1918, Bancroft (NSW, holo; K, iso)', while Maiden cited 'Eidsvold, Queensland (Dr T.L. Bancroft, No. 32, with photo)' for the taxon on which Pedley based $A$. caroleae. At NSW there are seven sheets of 
A. caroleae collected from Eidsvold by Bancroft, four of which include the number ' 32 ', but covering three collection dates: May 1917, August 1918 and November 1918. Because of the no. 32 being used in this way for different collections of the same species, there appears to have been confusion in the past when writing labels where a flowering specimen (NSW 417142) has been stamped 'NOV 1918' (which should probably be August since the main flowering time for this species is July to October) and a sheet with bagged legumes and seeds (NSW 417148) is dated '8-1918' (which should probably be November). Although Pedley cited 'Aug 1918' as the type there are a number of possible syntypes covered by Maiden's reference to Bancroft 32, thus it was felt desirable to lectotypify the species to avoid confusion.

The earliest collection of Bancroft 32 at NSW is May 1917 (NSW 417155), which is possibly associated with the photo referred to in Maiden's description. The specimen is practically sterile (only small, very immature buds present), more or less agreeing with the black and white photo of a shrub which appears to show few signs of flowers or fruit (though the quality of the photo makes it difficult to distinguish what might possibly be legumes). If this specimen came from the shrub photographed it could be considered the holotype of $A$. doratoxylon var. angustifolia (and therefore A. caroleae) if one was to take the view that Maiden intended only to refer to Bancroft 32 with the photo as the type. However, the origin of the photograph is uncertain and I interpret Maiden's citation of Bancroft 32 as reference to a collection of Bancroft specimens which includes photos showing the habit of the species (a view reinforced by the fact that the photos are not included in any of the sheets).

The sheet NSW 417151 is selected as the lectotype because it has mature legumes and seeds and a tag tied onto a branchlet with the note 'No. 32 shrub $8 \mathrm{ft}$ in height ...' in Bancroft's hand (agreeing with the reference to 'shrub eight feet in height' in the protologue).

At K there is a Bancroft 32 sheet (ex NSW) dated '8/1918' with flowering and fruiting specimens (K. Hill, pers. comm.), which is probably a mixed collection of August flowering material (?paralectotype) and November fruiting material (?isolectotype), but this requires further investigation. A flowering specimen (NSW 136982 ex BRI) with no collection number or date is of uncertain status.

\section{Acacia cheelii Blakely, Proc. Linn. Soc. New South Wales 42: 441 (1917)}

T: Manilla, N.S.W., Sep 1916, L.H. Preston; lecto (flowering specimen): NSW 260043, fide M.D. Tindale et al., Austral. Syst. Bot. 5: 651 (1992); Manilla, N.S.W., Dec 1916, L.H. Preston; paralecto (fruiting specimen): K n.v., NSW 260044; Manilla, c. 10 miles [16 km] from town, H. Stoddart, Sep 1916; paralecto (flowering specimen): K, NSW 260061.

In the protologue Blakely cited the type locality as 'Manilla, New South Wales (L.H. Preston and H. Stoddart; flowers, September; and fruits, December, 1916)', thus covering all three specimens cited above which match the description and were presumably seen by Blakely. Although not explicitly stated 'chosen here' the lectotype NSW 260043 was cited by M.D. Tindale et al., loc. cit., with the remaining type specimens as syntypes (here referred to as paralectotypes).

Further flowering material collected from Manilla by Stoddart in October 1916 (K n.v., MEL \& MEL n.v., MO, NSW 34465, PERTH) includes an ex NSW label with the words 'Portion of Type', possibly in Blakely's hand. However, this is not treated here as type material since the October date is not mentioned in the protologue. However, because (i) this material is very similar to the material collected by Stoddart in September 1916, (ii) it is unusual that it was not cited by Blakely (i.e. flowering to include October), and (iii) the ex NSW label has 'Manilla' and '10-1916' written in a hand other than Blakely's, there is a possibility that it is duplicate type material (belonging to NSW 
260061) that was meant for distribution but has the wrong date and an abbreviated location on the label. There appears to be a duplicate of this material in the type folder for $A$. cheelii at K (K. Hill, pers. comm.) and MEL (n.v., with 'Type' on ex NSW label).

6. Acacia rhodoxylon Maiden, J. E Proc. Roy. Soc. New South Wales 53: 223, pl. 16, figs 5-12 (1919, published 1920)

T: Eidsvold, Qld, Mar 1918, T.L. Bancroft 19; lecto (here chosen): NSW 416912; isolecto: K n.v.; Eidsvold, Qld, Nov 1918, T.L. Bancroft 19; paralecto: BRI (without legumes), NSW 416916.

Maiden in the protologue cites the type as 'Dr. T.L. Bancroft, No. 19, Eidsvold, Queensland'. At NSW there are three sheets of Bancroft 19 collected on three different dates, i.e. March, August and November 1918. The number '19' is therefore likely to refer to Bancroft's species/plant number rather than to an individual collecting number. Because there has been confusion in the past (e.g. 'Eidsvold, Bancroft 19' was cited as the holotype at NSW by L. Pedley, Austrobaileya 1: 149, 1978 it was considered desirable to choose a lectotype from the relevant material at NSW.

The sheet NSW 416912 (containing two flowering branchlets) is chosen as the lectotype, as it fits the protologue description and details of a phyllode and flower from this specimen were drawn by Margaret Flockton for Plate 16 (fig. 6 - phyllode, figs 7-10 - spike, flower, ovary \& bracteole), as indicated by the artist inside the specimen folder as well as on the original pencilled line illustration (both dated 17 Oct 1919).

The November 1918 specimen contains only a few (immature or poor) legumes, with NSW 416916 including a branchlet with juvenile phyllodes. Margaret Flockton indicated inside the specimen folder of NSW 416916 that she used this material to draw the juvenile phyllode and pod, Plate 16, figs 5 and 11, respectively. The seed (Plate 16, fig. 12 ) was probably based on this material.

The August 1918 specimen (BRI, K, NSW 416913) contains mature legumes and seeds, as well as a few old flowers. On the NSW sheet there is an attached envelope containing old legumes of this species collected by Bancroft on 10 November 1921; this element thus has no type status since the collection date is after publication of the species. However, it also appears that Maiden had not seen the August 1918 material at the time of writing the protologue. This is deduced from the fact that Maiden describes $A$. rhodoxylon as 'a shy fruiter and the pods not seen fully ripe', the pod 'about $3 \mathrm{~cm}$ long' and seeds 'shiny black'. This does not account for the August 1918 material which contains mature legumes to $5.5 \mathrm{~cm}$ long with shiny brown seeds, hence it is not accepted here as type material.

7. Acacia rothii F.M. Bailey, Queensland Agric. J. 6: 39, pl.161 (1900)

T: mouth of the Batavia River, Qld, W.E. Roth; holo: BRI n.v., fide L. Pedley Austrobaileya 1: 222 (1978): iso: NSW 416904.

The type material previously was only cited for BRI. However, a specimen sent to NSW stamped 'COLONIAL BOTANIST, Brisbane' with the annotation 'Queensland 7.1904' can be considered an isotype. This material was sent after the publication date of the species, therefore Bailey is likely to have seen this specimen when preparing the description. It consists of three phyllodes, as well as part of a phyllode and a legume with two immature seeds (now separated from pod). Although the label provides the location as 'Batavia River' with no collector, it is likely to be part of the type material; it was possibly sent as such and the legume is an excellent match for the one illustrated in Plate 161 of the protologue. In fact, the legume of NSW 416904 is very likely to be the one used for the illustration, but BRI material would need to be checked to confirm this. 
8. Acacia shirleyi Maiden, J. E Proc. Roy. Soc. New South Wales 53: 218, pl. 15, figs 8-14 (1919, published 1920)

T: Mt Rose, Eidsvold, Qld, 7 Nov 1912, T.L. Bancroft 14 (fruiting specimen); lecto (here chosen): NSW 371836; isolecto: BRI; ditto (young tree); paralecto: NSW 417184; [Mt Rose], Eidsvold, Qld, Mar 1918, T.L. Bancroft 14 (flowering specimen); paralecto: K n.v., NSW 371834 \& 371835; possible paralecto: see below.

Maiden cites the type 'from Mount Rose, Eidsvold, Queensland (Dr. T.L. Bancroft, No. $14)^{\prime}$, which covers a range of specimens with Bancroft's number '14'. There are flowering specimens collected in March 1918 and fruiting specimens collected on 7 November 1912 and again in November 1918. The NSW 371836 specimen has been selected as lectoype because: (i) it fits the protologue description; (ii) it would have been seen by Maiden, (iii) it contains labels annotated by Bancroft; and (iv) Maiden (page 20 of protologue) cites 'No. 14 of 7th November, 1912' quoting the collector's notes on the specimen. L. Pedley in Austrobaileya 1: 152 (1978) cited this specimen as a holotype with isotypes at BM and K. There are two sheets at NSW of fruiting material collected by Bancroft in November 1918: Bancroft s.n. containing branchlets, legumes and seeds (NSW 371903) and Bancroft 14 containing a large bag of legumes and seeds (NSW 371837), both being possible paralectotypes as would the BM and K specimens if they are November 1918 collections. The K sheet is a mixed collection of '3-1918 Flowers/11-1918 Pods' (K. Hill, pers. comm.). A fruiting specimen (NSW 371904 ex BRI) and a flowering specimen (MEL 257638 ex BRI, n.v.), neither of which have a collection number or date, are of uncertain status.

A branchlet from a 'young tree', originally placed with the fruiting 1912 material, and the flowering material collected in March 1918 (cited by Maiden on page 20) have been designated as paralectotypes.

\section{Acknowledgments}

These notes were compiled during the editing of the Flora of Australia manuscript on Acacia, funded by Australian Biological Resources Study, Canberra. I am grateful for the advice of Drs Peter Wilson, Mary Tindale and Barry Conn. Ken Hill (A.B.L.O., Kew) kindly provided information on specimens at K. I thank Dr Jim Ross (MEL) for investigating and providing details on specimens at MEL, and for commenting on the manuscript. 


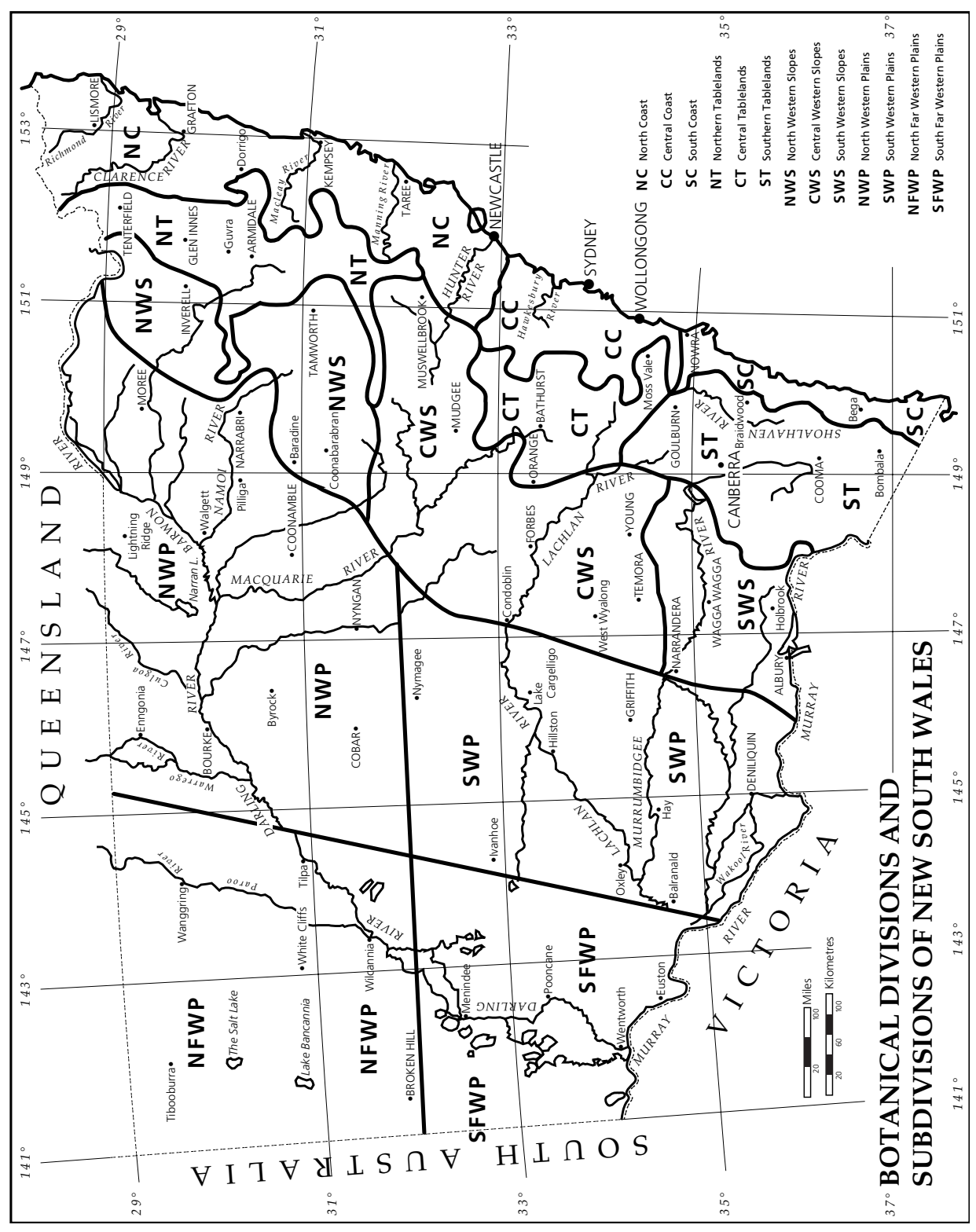

For explanation and description of the Botanical Divisions and Subdivisions of New South Wales see Anderson, R.H. (1961). Introduction. Cont. New South Wales. Natl. Herb. Fl. New South Wales Nos 1-18, pp. 1-15. 